\title{
Do physical barriers hamper dispersal in the deep sea?
}

\author{
Lidia Lins $^{1,2, *}$, Sofie Derycke ${ }^{3}$, Tania Nara Campinas Bezerra ${ }^{1}$, Ann Vanreusel ${ }^{1}$ \\ ${ }^{1}$ Marine Biology research group, Ghent University, Krijgslaan 281 S8, 9000 Ghent, Belgium \\ 2 Senckenberg Research Institute and Natural History Museum, Senckenberganlage 25, 60325 Frankfurt am \\ Main, Germany \\ 3 OD Taxonomy and phylogeny, Royal Belgian Institute of Natural Sciences, Vautierstraat 29, 1000 Brussels, \\ Belgium
}

*Corresponding author: lidia-lins@hotmail.com

\begin{abstract}
The presence of topographic features, such as mid-ocean ridges, can divide the abyss into basins, which can be interconnected through gaps and potentially affect species distribution and dispersal. Holding endemic and widespread species, nematodes represent ideal organisms to study species-range sizes, dispersal, distribution, and turnover in the deep sea. On board of the RV Sonne to the Vema Fracture Zone (VFZ), our study aimed to investigate if: a) The VFZ represent a barrier to gene flow; b) Genetic differentiation increase with increasing geographic distance; c) Species-range size for nematodes $(<100 \mathrm{~km}$ vs. $>1000 \mathrm{~km})$ ?. Based on integrative taxonomy (molecular and morphology-based methods) and community analyses, our results suggest no geographical trend, indicating a weak correlation between genetic divergence and geographical distance. Nevertheless, most species were restricted to one area $(62.5-76 \%)$, while $24-37.5 \%$ of the species were shared between areas. These results suggest that the VFZ may not limit dispersal completely, reacting like a sharp boundary, but it might act as a transition zone, restricting dispersal. Additionally, our results bring new insights on species turnover and species-range sizes in the deep sea, which will help to manage and estimate the potential impacts of anthropogenic activities.
\end{abstract}

Keywords: connectivity, Mid-Atlantic Ridge, Vema Fracture Zone, intraspecific divergence

\section{Short description}

This study investigated the role of the Vema-Fracture-Zone as a barrier for dispersal in abyssal areas. 